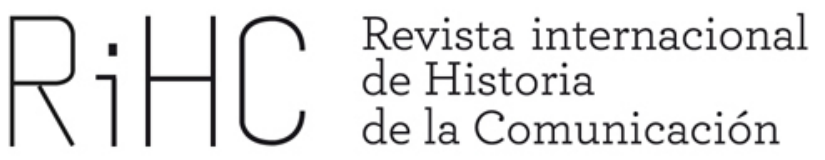

\title{
LA SEGUNDA EDAD DE ORO DEL HUMOR GRÁFICO GALLEGO (1982-2000)
}

DOI: http://dx.doi.org/10.12795/RiHC.2015.i04.09

Félix Caballero Wangüemert

Universidad de Vigo

felixcaballero@hotmail.com

Recibido: 25-5-2015

Aceptado: 11-6-2015

Resumen: Hacia 1970 comienza en el humor gráfico gallego una etapa de resurgimiento, después de más de tres décadas de censura y decadencia, que se confirmará en los años 80 y 90. El periodo comprendido entre 1982 y 2000 puede ser calificado como la segunda edad de oro del humor gráfico gallego, después de la primera y genuina, la protagonizada por Castelao y los humoristas de su generación entre 1909 y 1936. Este esplendor viene dado por el trabajo de dibujantes como Quesada, Siro, Xaquín Marín, Xosé Lois, Chichi Campos, Gogue y Pepe Carreiro, y por tres grandes acontecimientos para el género: la celebración de los encuentros de humoristas, la publicación de las revistas de humor Can sen Dono, Xó! y Sapoconcho, y la fundación del Museo do Humor de Fene.

Palabras clave: Humor gráfico, prensa gallega, edad de oro, resurgimiento

Abstract: Towards 1970 begins in the Galician cartoon a revival stage, after more than three decades of censorship and decadence, that will be confirmed in the years 80 and 
90. The period between 1982 and 2000 can be qualified as the second golden age of Galician cartoon, after the first and genuine one, starring Castelao and the cartoonists of his generation from 1909 to 1936. This splendour is given by the work of illustrators such as Quesada, Siro, Xaquín Marín, Xosé Lois, Chichi Campos, Gogue and Pepe Carreiro, and by three major events for the genre: the meetings of cartoonists, the journals of humour (Can sen Dono, Xo! and Sapoconcho) and the Museum of Humour in Fene.

Keywords: Cartoon, Galician press, golden age, revival

\section{Introducción}

\subsection{Exposición de motivos}

La Guerra Civil truncó la edad de oro del humor gráfico gallego, iniciada en 1909 con la revista viguesa Vida Gallega, y dio paso a una larga etapa de mediocridad de la que solo se salvaron algunas excepciones (Atomé, Quesada...). A finales de los años 60, la rica tradición del humor gráfico gallego de antes de la Guerra (Castelao, Maside, Cebreiro, Torres...) se había perdido y los nuevos humoristas estaban influidos fundamentalmente por La Codorniz.

Hacia 1970, con la irrupción de Siro y Xaquín Marín, comienza tímidamente una nueva etapa de recuperación del prestigio social del género y de la tradición perdida, que se verá confirmada en los años 80 y 90 con una serie de acontecimientos felices para el humor gráfico gallego: la apertura de los diarios a los humoristas autóctonos comprometidos con la lengua y la cultura del país, la celebración de los Encontros de Humoristas Galegos, la publicación de las primeras revistas de humor gráfico gallego desde la Guerra Civil (Can sen Dono, Xó! y Sapoconcho) y la fundación del Museo do Humor de Fene.

Las décadas de 1980 y 1990 pueden ser consideradas las más importantes de la historia del humor gráfico gallego después de las de 1910, 1920 y 1930 (hasta la Guerra Civil), cuando Castelao y los humoristas de su generación publicaron lo mejor de su obra en la revista Vida Gallega y en los principales diarios de la región, como Galicia (el primero que puso la viñeta en portada), Faro de Vigo (en el que Castelao desarrolló la mayor parte de su serie Cousas da vida), El Pueblo Gallego, La Voz de Galicia o El Ideal Gallego. 


\subsection{Metodología}

Este es un estudio de carácter fundamentalmente histórico, basado en el análisis de fuentes primarias, como el Manifesto en defensa do humor de Siro y Xaquín Marín (1983) o las ponencias y comunicaciones del I Seminario Galego do Humor de Sada (1982), así como en una selección de la obra humorística de Quesada, Siro, Xaquín Marín, Xosé Lois, Chichi Campos, Gogue y Pepe Carreiro. En este sentido, se han consultado las siguientes antologías:

a) QUESADA, Fernando (2011). Quesada. 1961-2011. Vigo: Faro de Vigo.

b) LÓPEZ, S. (2009). A autonomía galega nas caricaturas de Siro. A Coruña: Deputación da Coruña.

c) MARÍN, X. (1997). Feito a man. Santiago de Compostela: Consellería de Cultura da Xunta de Galicia.

d) XOSÉ LOIS (2002). 20 anos de Carrabouxo. Ourense: Deputación Provincial de Ourense.

e) CAMPOS, X. (1993). Xesús Campos. Unha visión aguda e vertixinosa de Galicia. Santiago de Compostela: Consorcio da Cidade de Santiago. Catálogo da exposición do mesmo título presentada en el Museo do Pobo Galego de Santiago de Compostela en septiembre/octubre de 1993.

f) GOGUE (2011). Historias Floreánicas II. O Grove: Todogrove.

g) CARREIRO, Pepe (1997). Fraga na Galiza. Santiago de Compostela: Laiovento.

El corpus de las fuentes se completa con una serie de entrevistas realizadas por el autor a cinco de esos siete humoristas: Siro, Xaquín Marín, Xosé Lois, Gogue y Pepe Carreiro. Dos de ellas fueron hechas en el transcurso de una investigación para una tesis doctoral sobre Xaquín Marín, y tuvieron por protagonistas al propio Marín (entrevista personal, Fene [A Coruña], 4-10-2012) y a Siro (entrevista personal, A Coruña, 17-2-2012). Las otras habían sido realizadas con anterioridad para el libro $O$ humor en cadriños, publicado por el autor en 2012. Las fechas en que tuvieron lugar fueron estas: Siro (comunicación electrónica, 10-11-2010), Xaquín Marín (comunicación electrónica, 3-12-2010), Xosé Lois (comunicación electrónica, 24-122010, Gogue (comunicación electrónica, 1-12-2010) y Pepe Carreiro (entrevista personal, Vigo [Pontevedra], 21-2-2011). 


\subsection{Hipótesis}

a) En las décadas de 1980 y 1990, el humor gráfico gallego vivió un despertar, apuntado ya desde 1970, que le permitirá recuperar el prestigio social y profesional que tuvo antes de la Guerra Civil y vincularse, al menos en parte, a la rica tradición perdida con la contienda (la de Castelao, Cebreiro, Maside, Torres y tantos otros).

b) El periodo 1982-2000 es el más importante de la historia del humor gráfico gallego desde la edad de oro del género (1909-1936), por lo que puede ser calificado de la segunda edad de oro.

\section{La edad de oro del humor gráfico gallego (1909-1936)}

La aparición en Vigo en 1909 de la revista Vida Gallega inaugura la llamada edad de oro del humor gráfico gallego, en la que Alfonso Daniel Rodríguez Castelao ${ }^{1}$ creará propiamente la moderna caricatura gallega a partir de la galleguización de la caricatura modernista, que había puesto de moda en toda Europa la revista alemana Simplicissimus $^{2}$, en la que sobresalía, entre otros caricaturistas, el noruego Olaf Gulbransson $^{3}$ (López, 1996: XXX). El rianxeiro revolucionará el humor gráfico gallego con un trabajo en el que destacan la serie Cousas da vida, iniciada en el diario vigués Galicia en 1922 y continuada luego en Faro de Vigo, y el álbum Nós, publicado en 1931, pero con estampas realizadas entre 1916 y 1918.

Castelao creará enseguida escuela, y en un país donde existen pocos periódicos y menos lectores llegará a haber cerca de cien caricaturistas que publican humor gráfico con textos en gallego o bilingües: Maside, Cebreiro, Torres, Vidales Tomé, Prada,

\footnotetext{
${ }^{1}$ Alfonso Daniel Rodríguez Castelao (Rianxo, A Coruña, 1886-1950). Médico, político, escritor, pintor y dibujante. Uno de los padres del nacionalismo gallego. Cofundador del Partido Galeguista. Impulsor del Estatuto de Autonomía de Galicia. Diputado en Cortes durante la II República. Ministro sin cartera del Gobierno republicano en el exilio. Tras la Guerra Civil se exilió en Nueva York y luego en Buenos Aires, donde murió. De niño ya había vivido emigrado en Argentina. Como escritor es autor de las prosas Cousas, la obra de teatro Os vellos non deben de namorarse y el ensayo político Sempre en Galiza, entre otras muchas obras.

${ }^{2}$ Simplicissimus (1896-1967) constituye "un verdadero monumento de la cultura alemana" en el siglo XX. Contó con colaboradores literarios de la categoría de Thomas Mann, Rilke ou Schnitzer, pero fue en la gráfica donde marcó una era, imponiendo la caricatura síntesis en todo el mundo, con dibujantes como Heine, Grosz, Blix y Gulbransson, entre otros muchos (López, 1996).

${ }^{3}$ Olaf Gulbransson (Oslo, Noruega, 1873-1958) fue uno de los principales dibujantes de Simplicissimus, donde comenzó a colaborar en 1902. Referente internacional de la caricatura síntesis, Intentó simplificar todas las múltiples formas de la naturaleza en unas pocas fórmulas expresivas, y apresar en un trazo cada gesto y en unas pocas líneas el carácter del modelo (López, 1996).
} 
Romano, Ribas, Fernández Mazas... ${ }^{4}$. Entre ellos figuran algunos de los artistas que renovarán la plástica gallega en el siglo XX, como Maside, Torres, Seoane o Laxeiro. Algunos de estos humoristas colaborarán también en la prensa madrileña, en concreto en el diario El Sol, como Castelao, Maside, Cebreiro y Torres, este último con viñetas en gallego.

\section{Las décadas oscuras (1936-1970)}

La Guerra Civil truncó la edad de oro del humor gráfico gallego (1909-1936) y supuso una ruptura total con la edad de oro. Algunos de los caricaturistas de la etapa anterior fueron fusilados (Díaz Baliño, Huici...), otros marcharon al exilio (Castelao, Ribas, Seoane...) y los que se quedaron aquí fueron obligados a callar.

Cebreiro, Torres y Vidales Tomé volvieron fugazmente después de la contienda bélica, pero sin el empuje anterior ${ }^{5}$, y el humor gráfico gallego entró en una etapa de censura y mediocridad -en tres largas décadas oscuras- de la que apenas se salvaron algunos pocos nombres: Atomé, Lalo, Quesada...

Atomé (Antonio Tomé Taboada, 1915-1974) trabajó para El Ideal Gallego de A Coruña desde 1965 hasta su muerte en 1974. Su dibujo y sus textos recuperan lo mejor de la tradición perdida de la generación de Castelao, pero las difíciles circunstancias de la época (la precariedad, la censura, la represión, la hostilidad del régimen hacia las lenguas vernáculas...) y el poco eco del diario en el que colaboraba (el segundo de la ciudad herculina, muy lejos de La Voz de Galicia) impidieron que le devolviese al humor gráfico gallego el papel y la tradición que le correspondían ${ }^{6}$.

\footnotetext{
${ }^{4}$ Clodio González Pérez ha realizado muchos trabajos sobre estos autores de la generación de Castelao, incluidas las siete monografías de la colección Os Nosos Humoristas de Ediciós do Castro -Castelao (1982), Vidales Tomé (1982), Padín (1983), Maside (1983), Prada (1984), Torres (1985) y Cebreiro (1986) - y un libro en que ofrece semblanzas de 50 de ellos (1986).

${ }^{5}$ Álvaro Cebreiro Martínez (A Coruña, 1903-1955) colabora a partir de 1950 en el diario coruñés El Ideal Gallego hasta su muerte, el 9 de noviembre de 1955. El periódico publicaría después de su fallecimiento un libro con una selección de sus viñetas: Dibuxos de Cebreiro, A Coruña, 1958. Manuel Torres Martínez (Marín, Pontevedra, 1901-1995) retoma el humor gráfico en La Voz de Galicia de A Coruña entre 1962 y 1964. Ignacio Vidales Tomé (Ponteareas, Pontevedra, 1896-1963) publica en Faro de Vigo viñetas de fútbol entre 1955 y 1957.

${ }^{6}$ Sobre Atomé, se puede consultar el libro GONZÁLEZ PÉREZ, C. (2000). Atomé. O debuxante e humorista de Santa Comba. Santa Comba: Asociación Cultural "Comarca do Xallas".
} 
Lalo (Bernardo Vázquez Gil 1927) colaboró entre 1954 y 1979 en El Pueblo Gallego de Vigo, donde convirtió en popular a su personaje Gorechiño ${ }^{7}$.

Quesada (Fernando Quesada Porto, 1933) empezó en Faro de Vigo en 1961 haciendo caricatura internacional (Nixon, De Gaulle, Mao Tse Tung, Golda Meir...), una de la pocas vías de escapa que tenían los humoristas de la época.

A finales de la década de 1960, el hacer de los nuevos humoristas gallegos estaba más influido por La Codorniz ${ }^{8}$-y especialmente por Mingote- que por cualquier otra cosa ${ }^{9}$ (López, 1997). En la mítica revista colaboraban dos dibujantes gallegos -Abelenda y Julio Cebrián, ganadores los dos del Premio Paleta Agromán-, y en los años 70 aún lo harían Xaquín Marín y Quesada. Incluso Pepe Carreiro llegó a publicar dos dibujos.

\section{El resurgimiento (1970-2000)}

\subsection{Los inicios de una nueva era (1970-1982)}

En este contexto, hacia 1970 Siro y Xaquín Marín se inician en el humor gráfico colaborando en Chan $^{10}$, la revista gallega que dirigía en Madrid el compostelano Raimundo García Domínguez, más conocido como Borobó, una de las figuras claves del

\footnotetext{
${ }^{7}$ Sobre Gorechiño, existe la antología VÁZQUEZ GIL, L. (1978). Cousas de Gorechiño. Vigo: Gráficas Alpima.

${ }^{8}$ La Codorniz fue la revista española de humor gráfico más importante del siglo XX. Fundada por Miguel Mihura (Madrid, 1905-1977), cultivó, sobre todo en sus inicios, un humor surrealista y absurdo. En 1944, Mihura vendió la revista al conde de Godó y la publicación pasó a ser dirigida por Álvaro de Laiglesia, que le imprimó un sello más social, sin exagerar (al fin y al cabo, hasta 1966 siguió vigente el sistema de censura previa impuesto por el franquismo durante la Guerra). En la revista marcaron época dibujante como Tono, Herreros, Gila, Mingote o Chumy Chúmez. Entre los estudios sobre la publicación destaca especialmente LLERA RUIZ, J.A. (2003). El humor verbal y visual de La Codorniz. Madrid: CSIC.

${ }^{9}$ La rica tradición del humor gráfico de antes de la Guerra había caído en el olvido. Las nuevas generaciones no conocían la obra de Castelao. Sus Cousas da vida no se recuperaron hasta que Galaxia publicó una amplia selección en siete volúmenes. El primero salió en 1961 y el segundo en 1968, pero los otros cinco no vieron la luz hasta 1971.

${ }^{10}$ Chan fue una revista quincenal gallega editada en Madrid entre 1969 e 1971 . Salieron un total de 38 números. Escrita mayoritariamente en castellano, abrió espacios al gallego y fue relativamente aperturista en general. Se hicieron comentarios sobre la obra de Castelao y se reprodujeron algunos de los cuadros de "Cousas da vida".
} 
periodismo gallego. Ahí Siro publicó en 1970 sus Nenos y Marín en 1971 O Emigrante, su primer cómic.

Gónzalez Pérez (1984) considera estas dos colaboraciones el punto de partida de una nueva etapa en el humor gráfico gallego, que pone fin a las décadas oscuras y supone la recuperación, por una parte, del prestigio perdido, y por otra, de la identidad gallega, sobre todo a través de la escritura (la mayoría de los humoristas escribirán en gallego) y en menor medida, también del dibujo, que en algunos casos (Siro, Xaquín Marín, Pepe Carreiro) beberá claramente de las fuentes de la tradición de Castelao, Maside, Cebreiro, etc., aunque siempre con peculiaridades e innovaciones.

Pero el camino se andará despacio. Los años 70 son solo el prólogo de los dos decenios que, efectivamente, confirmarán el resurgimiento del humor gráfico gallego y que podríamos calificar de auténtica segunda edad de oro. Al estreno de Siro y Xaquín Marín en Chan hay que sumar otros hitos: en 1970, Quesada publica en Faro de Vigo sus primeras viñetas en gallego; en 1971, Siro inaugura la moderna caricatura política gallega en Ferrol Diario y en 1972 empieza a colaborar en El Ideal Gallego de A Coruña; en 1975, Xaquín Marín se incorpora también a El Ideal, después de haber colaborado en Madrid en Hermano Lobo y La Codorniz... Hacia 1975 sólo había cuatro humoristas en la prensa gallega que publicaban en gallego, y no siempre (Siro, Xaquín Marín, Quesada y Lalo).

Quesada, sin duda el humorista gráfico gallego más conocido en el resto de España por sus colaboraciones en la prensa madrileña desde los años 60 (Pueblo, Arriba, La Codorniz, Cambio-16, Blanco y Negro, Interviú...), alcanzó en los 70 una popularidad inusitada en Galicia, sobre todo en la zona de influencia de Faro de Vigo, debido a los cinco libritos de la serie Chispas da roda, publicados en la colección O Moucho de Edicións Castrelos $^{11}$, que fueron reeditados continuamente y convirtieron al autor en el más vendido de todo el sistema editorial gallego, según Méndez Ferrín (Quesada, 2011: 5).

En la década de 1970 debemos diferenciar dos subetapas: antes y después de 1977. La primera se corresponde todavía con el tardofranquismo y el franquismo sin Franco. La Ley de prensa de Manuel Fraga, de 1966, había derogado la censura previa, pero en España no habrá verdadera libertad de expresión hasta que la Constitución de 1978, aprobada en referéndum el 6 de diciembre de 1978 y en vigor desde el 29 de diciembre del mismo año tras su publicación en el Boletín Oficial del Estado (BOE),

\footnotetext{
${ }^{11}$ Fundada por el poeta Xosé María Álvarez Blázquez, la colección O Moucho significó un hito en la historia del libro gallego, excediendo los campos intelectuales y en cierto modo elitistas a los que se había dirigido tradicionalmente para abrirse a lo popular. Su objetivo principal era introducir la lengua gallega en los hogares. Los libros alcanzaron una distribución desconocida en Galicia. Salieron de las librerías y se vendieron en tabernas, ferreterías, ferias y mercados. El activismo cultural de la época y el bajo precio de los libros (30 pesetas) favorecieron su difusión. Del Catecismo do labrego, de Valentín Lamas Carvajal, se tiraron 100.000 copias.
} 
recoja y proteja el derecho a la información y la libertad de expresión, permitiendo solo el secuestro de publicaciones "en virtud de resolución judicial".

El panorama había empezado a cambiar en 1977 con la puesta en marcha de la Transición. El Real Decreto-Ley 24/1977, de 1 de abril, suprimió parcialmente el secuestro administrativo de publicaciones (se mantenía en casos de informaciones contrarias a la unidad de España, la Monarquía o las Fuerzas Armadas) y derogó el polémico artículo 2 de la Ley Fraga, por el que se sometía la libertad de expresión a los Principios del Movimiento Nacional. Otro decreto, el Real Decreto-Ley 23/1977, de 1 de abril, sobre reestructuración de los órganos dependientes del Consejo Nacional y nuevo régimen jurídico de las asociaciones, funcionarios y patrimonio del Movimiento, desmanteló formalmente la estructura de los medios de comunicación al servicio del Movimiento y los adscribió a un organismo autónomo dependiente del Ministerio de Información y Turismo.

Prueba de que aún no había libertad de prensa a pesar de la muerte de Franco fue el doble proceso (militar y civil) que tuvo que afrontar Siro en 1976 por dos viñetas publicadas en El Ideal Gallego. El humorista ferrolano fue procesado por la justicia civil por ofender a la Magistratura de Trabajo con un cómic de seis viñetas inspirado en un artículo de Ciriaco de Vicente que acusaba a la Magistratura de Trabajo de atentar contra los trabajadores. El ministerio fiscal acabó retirando los cargos. Pero más grave resultó el consejo de guerra que se le dictó el 16 de diciembre de ese año por una viñeta publicada el 31 de octubre. El cuadro reproducía íntegramente en gallego el discurso final de El gran dictador, la película de Charles Chaplin que acababa de estrenarse en España después de haber estado más de treinta y cinco años prohibida. La viñeta llevaba por título “iLuchad por la libertad!", la frase final del discurso, dirigido a los soldados. La justicia militar acusó a Siro de sedición, y pidió para él seis años y un día de arresto mayor. El consejo de guerra no llegó a celebrarse por la amnistía general de octubre de 1977 (Siro, entrevista personal, A Coruña, 17-2-2012).

\subsection{La segunda edad de oro del humor gráfico gallego (1982-2000)}

\subsubsection{Hitos del humor gráfico gallego}

\section{1) El I Seminario Galego do Humor (1982)}

El auténtico resurgimiento del humor gráfico gallego no se producirá hasta la década de 1980, que confirmará el fenómeno apuntado desde 1970. El punto de partida es el I Seminario Galego do Humor, celebrado el 26 y el 27 de junio de 1982 en el Laboratorio 
del Castro, en Sada (A Coruña), bajo el magisterio de Isaac Díaz Pardo ${ }^{12}$, cuyo padre, el pintor Camilo Díaz Baliño, también había practicado el humor gráfico antes de la Guerra Civil. El encuentro reunirá a la práctica totalidad de los humoristas gallegos de la época (Quesada, Siro, Xaquín Marín, Chichi Campos, Xosé Lois, Gogue, Pepe Carreiro...), así como estudiosos del humor. Se aprobó la constitución de una secretaría permanente para recoger ideas y obra de cara a la concreción de un proyecto de una revista de humor gráfico, y Gogue y Pepe Carreiro presentaron su propio proyecto, Can sen Dono, que se materializaría unos meses más tarde, entrado ya 1983. Además, se presentaron seis ponencias y comunicaciones:

a) Eso da risa, a broma e mais o humor (Carlos Baliñas)

b) O humor como instrumento de autocrítica (Celestino Ledo)

c) Aproximación á historia do humor gráfico galego (Clodio González Pérez)

d) O cómic (Agustín Fernández Paz)

e) Notas para unha filosofía do humor (Siro)

f) A caricatura (Siro)

También en 1982, Ediciós do Castro, con Díaz Pardo al frente, comienza a publicar la colección "Os nosos humoristas", que permitirá rescatar la obra de siete de los grandes maestros de la edad de oro: Castelao (1982), Vidales Tomé (1982), Padín (1983), Maside (1983), Prada (1984), Torres (1985) y Cebreiro (1986). La colección estaba dirigida por Clodio González Pérez, autor de las siete monografías. Se completaba así el rescate de una generación que había empezado en 1971 con Castelao, cuando la Editorial Galaxia publicó Cousas da vida ${ }^{13}$.

\section{2) El Manifesto en defensa do humor (1983)}

Pero el punto de inflexión de este despertar del humor gráfico gallego en los años 80 lo constituyó la campaña que, a partir de enero de 1983 y durante dos años, llevaron adelante Siro y Xaquín Marín por toda Galicia con una exposición conjunta itinerante y la presentación del Manifesto en defensa do humor.

Los dos humoristas emprendieron "unha campaña en favor do humor galego" que, según ellos, "perigaba na súa singularidade e importancia". La iniciativa, que duró dos

\footnotetext{
${ }^{12}$ Tras abandonar las artes plásticas, en pleno reconocimiento de su labor, fundó con otros socios la fábrica de Cerámicas do Castro en el Castro de Samoedo (Sada) en 1947. En 1963 constituyó en Argentina, junto con otros destacados galleguistas, como Luis Seoane, el Laboratorio de Formas, precursor de otras actividades industriales y culturales como la restauración de la producción de cerámica de Sargadelos, en colaboración con Cerámicas do Castro (1963), la editorial Ediciós do Castro (1963), el Museo Carlos Maside (1970), el restaurado Seminario de Estudos Galegos (1970), el Instituto Galego de Información, etc. Su faceta más conocida fue la dirección y administración del Grupo Sargadelos.

${ }^{13}$ Eran siete volúmenes. El primero salió en 1961 y el segundo en 1968, pero los otros cinco no se publicaron hasta 1971.
} 
años, consistió en una exposición itinerante de viñetas de los dos "acompañada dun Manifesto en Defensa do Humor que denunciaba a inhibición de autoridades políticas e culturais en apoiar unha das principais peculiaridades dos galegos" (Marín, 1995: 11). Se trataba, en definitiva, de llamar la atención de sociólogos, críticos de arte, entidades culturales y medios de comunicación sobre la falta de atención en los últimos años para el humor, gráfico y literario, en Galicia.

El Manifesto tenía cuatro ideas fundamentales (López y Marín, 2009: 7):

a) Recordaba que, como había dicho Ramón Piñeiro" , "o humorismo é unha das calidades distintivas do espírito galego". Galicia "ten o humor como arma defensiva", "deu os únicos humoristas das letras españolas" y es una tierra donde "os humoristas anónimos xorden como cogumelos", "o sorriso intelixente é un esperanto entre as xentes de boa vontade" y "aínda sabemos sorrir 'a pesar de", señalaban.

b) Denunciaba que se había olvidado esta singularidad. Lo olvidaron los sociólogos, las entidades culturales, los críticos de arte, los responsables de los medios de comunicación, los responsables de las iniciativas empresariales..., decían.

c) Reivindicaba un trato de justicia para el humor: "Non pedimos para el un trato de favor, pero tampouco queremos velo abafado no outro extremo (...). Simplemente reivindicamos no seu nome un trato de xustiza".

d) Invitaba a todos a "participar na tarefa de dignificación do xénero, e, en concreto, do humor gráfico galego".

La campaña, en colaboración con la Caixa de Aforros de Galicia, llevó la exposición y el Manifesto a Ferrol, Santiago, A Coruña, Neda, As Pontes, Pontedeume, Pontevedra, Perlío (Fene), Vilagarcía de Arousa, Monforte y Sarria. En todas estas ciudades y pueblos el Manifesto fue presentado por intelectuales de gran prestigio, como Ramón Piñeiro o Domingo García-Sabell ${ }^{15}$.

El Manifesto en defensa do humor consiguió enseguida cuatro importantes frutos tangibles:

\footnotetext{
${ }^{14}$ Ramón Piñeiro López (Láncara, Lugo, 1915-1990). Figura histórica del galleguismo durante el siglo XX, su aportación fue decisiva para que, después de la Guerra Civil el Partido Galeguista en el interior abandonase la acción política y se centrase en la cultural, con la fundación de la editorial Galaxia y la revista Grial, entre otras actividades. Como escritor destacan sus aportaciones en el campo de la filosofía, la orientación lingüístico literaria y la traducción. Fue el primer presidente del Consello da Cultura Galega.

${ }^{15}$ Domingo García-Sabell Rivas (Santiago de Compostela, A Coruña, 1908-2003). Médico y escritor galeguista. Colaboró con Ramón Piñeiro, dirigiendo la editorial Galaxia en 1950. Senador por designación real en 1977. Presidente de la Real Academia Galega (1979-1997) y delegado del Gobierno en Galicia (1981-1996).
} 
a) La apertura de los diarios a los humoristas gallegos comprometidos con la lengua y la cultura del país.

b) Los Encontros de Humoristas Galegos.

c) Las primeras revistas de humor gráfico desde la Guerra Civil: Can sen Dono, Xó! y Sapoconcho.

d) El Museo do Humor de Fene

\section{3) Los Encontros de Humoristas Galegos (1984-1988)}

Los Encontros de Humoristas Galegos, conocidos también como los Encontros de Humoristas do Condado, por celebrarse en diversos municipios de esta comarca del sur de Pontevedra, fueron cinco y tuvieron lugar entre 1984 y 1988. La primera edición se desarrolló en Mondariz, en el Castillo de Vilasobroso, en 1984. Las cuatro siguientes se celebraron en Salvaterra do Miño (1985, 1986 y 1988) y O Porriño (1987). Los Encuentros tenían lugar en régimen de autoconvocatoria, aunque contaban con el respaldo de la Sociedade Cultural e Deportiva do Condado, y aprovechaban la infraestructura de su Festival de Poesía.

Aunque no se llegó a alcanzar ninguno de los objetivos prácticos perseguidos (el principal era la creación de una asociación de los humoristas gallegos), para su organizador en la sombra, Xosé Alberte Suárez Lage (comunicación telefónica, 25-92012), más conocido como Picho Suárez Lage, los Encuentros tuvieron un balance muy positivo porque contribuyeron al nacimiento de las revistas de humor, a la normalización del humor gráfico en la prensa diaria, a la sensibilización sobre las dificultades de la libertad de expresión y a la lucha contra la censura en los medios.

\section{4) Las revistas de humor (1983-2000)}

Tres fueron las revistas de humor que aparecieron en las décadas de 1980 y 1990: Can sen Dono (Vigo, 1983), Xó! (Vigo, 1991) y Sapoconcho (Fene, 1994). Su vida fue breve y, en el caso de las dos primeras, discontinua, pero su aportación al empoderamiento del humor gráfico en Galicia resultó notable.

El primer número de Can sen Dono ${ }^{16}$ salió en marzo de 1983. El proyecto había sido presentado en el I Seminario Galego do Humor de Sada. Se editaron 27 números cinco de ellos, extraordinarios- hasta abril de 1991, en dos etapas. De periodicidad mensual al principio, pasó luego a trimestral y finalmente a circunstancial (los últimos números aparecieron solo coincidiendo con acontecimientos puntuales como las elecciones, el referéndum de la OTAN, la Guerra del Golfo Pérsico, etc.). Estaba dirigida por Pepe Carreiro, coordinada por Gogue y editada por Antonio Mascato, aunque

\footnotetext{
${ }^{16}$ Can sen Dono y las otras dos revistas de humor gráfico que se publicaron en Galicia durante los años 80 y 90 (Xo! e Sapoconcho) han sido estudiadas pormenorizadamente por Alberto Pascual Carballo en su libro Humor gráfico galego. Da transición ao século XXI (Ir Indo, Vigo, 2009).
} 
como director de la segunda etapa, a partir de los Carnavales de 1989, figuraba Picho Suárez Lage. Se trataba de una revista abierta y plural, en la que colaboraron todos los humoristas que quisieron, sin obstáculo alguno, desde Quesada a Xaquín Marín.

Xó!, que vino a cubrir el hueco dejado por la definitiva desaparición de Can sen Dono, salió a la calle por primera vez en octubre de 1993. Se subtitulaba "A voz que para as bestas" $^{17}$. Se editaron 39 números en dos etapas, hasta marzo de 2000 . En la primera etapa salieron 18 números (del 0 al 17), hasta febrero de 1994, y en la segunda, 22 (del 18 al 39). Los números 20 a 37 llevaban un suplemento de cuatro páginas titulado Arre, la voz de las bostas de las bestias. La periodicidad empezó siendo semanal para pasar luego a mensual. Fue fundada por Suárez Lage (que figuraba como director), Pepe Carreiro y Claudio López Garrido. Antonio Mascato también participó activamente. Era una revista satírica, más tendenciosa que Can sen Dono.

Sapoconcho constituye un caso distinto. Era el boletín del Museo do Humor de Fene. De periodicidad trimestral, editó 19 números entre el 18 de diciembre de 1994 y el 19 de enero de 2000, además de dos extraordinarios, sobre las XI e las XII Xornadas de Humor del Museo, con fecha de 27 de abril de 1996 y 26 de abril de 1997, respectivamente. Editado con la colaboración del Ayuntamiento de Fene y de la Secretaría Xeral de Comunicación de la Xunta de Galicia, no tenía publicidad y era gratuito. Se enviaba la todo el mundo y en él colaboraron desinteresadamente grandes figuras del humorismo mundial. Tenía una perspectiva universal, con interés particular para los grandes dibujantes latinoamericanos y con una finalidad declarada de abrir cantera en Galicia.

\section{5) El Museo do Humor de Fene (1984)}

El Museo do Humor de Fene fue, sin duda, el acontecimiento más importante relacionado con el humor gráfico de todos cuantos tuvieron lugar en Galicia por esos años. $Y$ esto por dos motivos: porque se trataba del primer museo de humor de la península ibérica y uno de los pocos de todo el mundo; y por su sobresaliente papel como dinamizador del humor gráfico en toda Galicia.

Todavía hoy sigue siendo prácticamente el único museo de humor de España, porque las experiencias llevadas a cabo últimamente en El Toboso (Toledo), Torre de Juan Abad (Ciudad Real) y Casasimarro (Cuenca) presentan todavía un estado embrionario.

\footnotetext{
${ }^{17}$ Ya sabemos que para las revistas de humor gráfico los subtítulos no son una cuestión baladí. Recordemos que La Codorniz se proclamaba "La revista más audaz para el lector más inteligente" y Hermano Lobo, "Semanario de humor dentro de lo que cabe".
} 
Por otro lado, Osvaldo Macedo de Sousa ${ }^{18}$ (entrevista personal, 2-5-2013) calcula que a día de hoy los museos de humor en todo el mundo no pasan de unos treinta.

El Museo do Humor de Fene fue inaugurado el 25 de noviembre de 1984. Fundado y dirigido hasta 2008 por Xaquín Marín, sus fondos están formados por una sobresaliente selección de lo mejor del humor gráfico gallego, español e internacional. Sin embargo, lo más reseñable de esta entidad es la extraordinaria labor de divulgación y dinamización del humor gráfico en toda Galicia, especialmente mientras Marín fue su director, destacando sobre todo la convocatoria anual hasta 2007 de las Xornadas de humor y de los Premios Curuxa, además de la edición del boletín Sapoconcho entre 1994 y 2000.

\section{6) Otros acontecimientos felices para el género}

El impulso experimentado por el humor gráfico gallego desde 1982 llegó hasta entrado el nuevo siglo con otros acontecimientos felices para el género:

a) La Plaza del Humor de A Coruña, diseñada por Siro e inaugurada en 1990. Siro y Marín defendían la creación en las ciudades de paseos y espacios públicos dedicados al humor. La Plaza del Humor fue un encargo del Ayuntamiento de A Coruña al primero para que rehiciera la vieja Plaza de San Agustín. Siro diseñó una plaza con estatuas de Alfonso Daniel R. Castelao y Álvaro Cunqueiro, bustos de Julio Camba, Wenceslao Fernández Flórez y Vicente Risco, y caricaturas en el suelo de Honoré Daumier, George Grosz, Miguel de Cervantes, Francisco de Quevedo, Ramón María del Valle-Inclán, Eduardo Blanco Amor, Oscar Wilde, Antonio Mingote, Antonio Fraguas Forges, Astérix y Charly Rivel, entre otros.

b) La Bienal da Caricatura de Ourense, organizada por la Casa da Xuventude. La primera edición tuvo lugar el 19 y 20 de octubre de 1992, y la novena y última, del 5 al 30 de marzo de 2008. La enfermedad y posterior muerte de Benito Losada, alma máter de la Casa da Xuventude, y los recortes derivados de la crisis económica determinaron su desaparición. Constituyó un puente de unión con el humor gráfico portugués, que estuvo presente siempre desde la tercera edición con exposiciones y la participación de dibujantes lusos en las llamadas "fiestas de la caricatura".

c) Xatentendo.com, suplemento de humor gráfico del diario coruñés La Voz de Galicia, coordinado por Siro y Manuel Guisande. Constituyó un hito en la prensa española, no solo gallega. Como suplemento propiamente dicho (después siguió un poco más como sección del periódico) se editó durante un año. El primer número apareció el 24 de junio de 2000, y el último, el 16 de junio de 2001. Según Siro (entrevista personal, 172-2012), el suplemento tuvo una vida tan corta porque salió en un momento en que el

\footnotetext{
${ }^{18}$ Investigador, divulgador y dinamizador del humor gráfico, es el principal impulsor de los premios nacionales de humor gráfico que se conceden todos los años en Portugal desde 1987.
} 
editor de La Voz de Galicia, Santiago Rey, había dejado el periódico en las manos de su hijo Emilio, quien prescindió de todo el equipo directivo del padre y se rodeó de gente ajena al periodismo que no respaldó la iniciativa, con la única excepción del director, Bieito Rubido, que "apoiou o Xatentendo desde o primeiro día ata o derradeiro", pero "quedou só na súa defensa". Xatentendo.com tenía 16 páginas y se distribuía todos los sábados. Llevaba el subtítulo de "Arrobas de humor sin conservantes ni colorantes para un nuevo milenio".

d) O Farelo, suplemento de humor gráfico del periódico quincenal $A$ Peneira, editado en Ponteareas. Tenía una periodicidad mensual, ya que se entregaba con el número de la segunda quincena de cada mes. Estaba dirigido por Guillermo Rodríguez Fernández, director también del periódico. Se editó desde enero de 2001 hasta finales de 2009, poco antes del fin de $A$ Peneira. Su lema era "Revista de humor que rabea por peneirar".

\subsubsection{Humoristas principales}

Al resurgimiento del humor gráfico gallego contribuyó un gran número de dibujantes, cuyo rastro puede seguirse en el libro de Alberto Pascual Carballo Humor gráfico galego. Da transición ao século XXI (Ir Indo, Vigo, 2009), que incluye un glosario de todos los que colaboraron en las revistas Can sen Dono, Xó! y Sapoconcho. Los catálogos de la Bienal da Caricatura de Ourense también recogen unas pinceladas biográficas de todos los humoristas participantes en sus nueve ediciones.

Entre los humoristas gráficos que destacaron en la prensa diaria en estos años podemos distinguir tres generaciones, con una diferencia de solo un lustro entre ellas. La primera estaría representada por Siro y Xaquín Marín, nacidos ambos en 1943. La segunda la protagonizaría Xosé Lois, que nació en 1949. En la tercera sobresalen tres grandes nombres venidos al mundo alrededor de 1953: Chichi Campos (1952), Gogue (1953) y Pepe Carreiro (1954). La Asociación de Escritores en Lingua Galega (AELG) quiso reconocer su labor entregándoles en 2013 a todos ellos -excepto a Chichi Campos, fallecido hace más de veinte años- su premio Bós e Xenerosos, "pola súa defensa do idioma no ámbito do humor gráfico, que deu á luz unha obra na que vemos espellada a nosa realidade cunha visión crítica e esperanzadora" (AELG, 2013).

A todos ellos debemos añadir el nombre de Quesada (Ourense, 1933), que, aunque se inició en el oficio en la etapa anterior, con la tímida apertura de los 70 fue ensanchando los límites de la temática de sus chistes, explorando la cotidianidad de la cultura tradicional y empleando la lengua gallega como la principal de sus viñetas. Es entonces cuando aparecen sus personajes más característicos y divertidos: los labriegos maestros de la retranca, los afiladores que llevan media hora pidiendo paso entre el tráfico rodado, los emigrantes sentados en sus maletas, los albañiles y canteros que manejan petrodólares... 


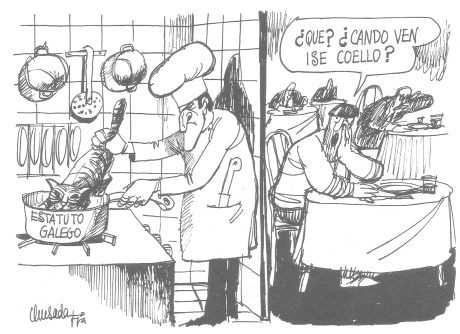

Figura 1: Quesada, Adolfo Suárez, Faro de Vigo, 1979

Todos estos humoristas son buena prueba de que el humor gráfico puede y debe ser considerado un género periodístico de opinión, como señalan cada vez más autores (Morán, 1988; Gomis, 1987 y 2008; Santamaría, 1997; Galindo, 2000; Barrero, 2007; Tejeiro y León, 2009; Paniagua, 2011). Todos ellos subrayan su semejanza con la columna e incluso con el editorial, a pesar de tener sus peculiaridades (Barrero, 2007: 31-32; Gomis, 1987: 244-246). Por eso, Paniagua (201: 162), en feliz juego de palabras, dice que la del humor gráfico no es solo una "opinión dibujada", sino también "desdibujada". La Constitución de 1978 consagró el derecho a la información y la libertad de prensa, y permitió así el libre ejercicio de la crítica periodística, también desde el humor gráfico. Esto impulsó, sin duda, el acercamiento del dibujo de humor al periodismo de opinión. En Galicia, el caso más acentuado quizás sea el de Siro, quien durante más de 20 años se encargó a diario de comentar gráficamente la noticia más importante de la política gallega. La viñeta acompañaba a la información en las páginas de "Galicia", en una práctica quizás única en toda España por su duración y sistematicidad.

Siro (Siro López Lorenzo, Ferrol, 1943) es, probablemente, el humorista que más se ha empeñado en vincular al humor gráfico gallego con la tradición iniciada con Castelao, al que ha estudiado pormenorizadamente y con el que fue comparado en sus inicios. Tras trabajar durante 30 años como caricaturista político en La Voz de Galicia, se retiró del oficio en 2006 para centrarse en la pintura y el ensayo. En la radio, entre otras iniciativas, dirigió el programa Corre Carmela que chove, que alcanzó una gran popularidad.

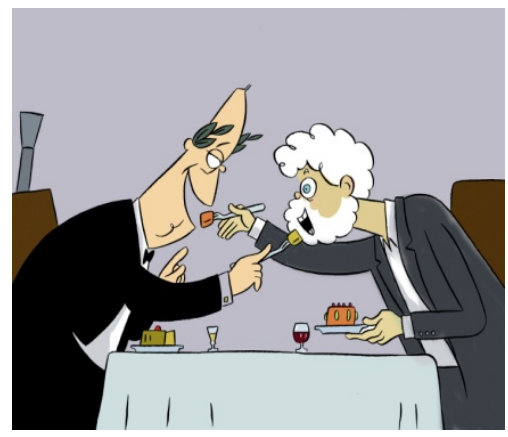


Xaquín Marín Formoso (Ferrol, 1943) está considerado el padre del cómic gallego junto al desaparecido Reimundo Patiño, con el que en 1975 publicó el libro Dúas viaxes. Como humorista colaboró en Hermano Lobo y La Codorniz antes de incorporarse a la prensa diaria gallega, primero en El Ideal Gallego (1975) y luego, desde 1988 hasta la actualidad, en La Voz de Galicia. Fue fundador y director del Museo do Humor de Fene (1984). Es el padre de personajes como Gaspariño o Isolino. No es solo uno de los mejores y más internacionales humoristas gráficos gallegos de los últimos cuarenta años, sino también y sobre todo, según el propio Siro, "o grande innovador do humor gráfico galego desde Castelao, aínda que a súa aportación resulte tan persoal que non posibilite a aparición de continuadores" (López, 1997: 18). El mérito de Marín consiste en haber transformado "a caricatura modernista alemana, galeguizada por Castelao, dotándoa dunha forza e solidez que fan recordar o mellor das nosas artes románica e barroca" (López, 1997: 18).

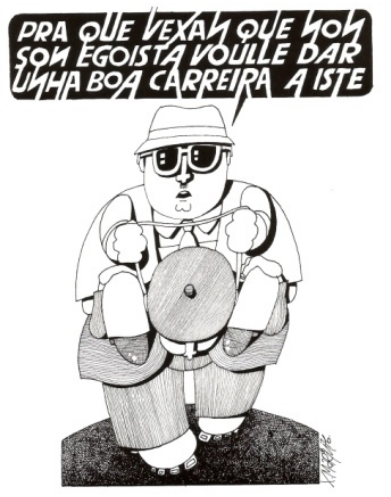

Figura 3: Xaquín Marín, El Ideal Gallego, 1976.

Xosé Lois (Xosé Lois González Vázquez, Ourense, 1949) es uno de los humoristas gráficos gallegos que mejor domina el juego de palabras. Consiguió una popularidad que, por veces, recuerda a la de Quesada en los años 70 y 80 . De hecho, su personaje O Carrabouxo (que dibuja en La Región desde 1982) puede presumir de haber conseguido una cosa verdaderamente insólita en un ser de ficción: tener una estatua propia. Mafalda, la inolvidable niña de Quino, es uno de los pocos personajes de humor gráfico inmortalizados en estatua (en Buenos Aires, en el barrio de San Telmo). La de O Carrabouxo, hecha por el escultor César Lombera, fue levantada en 2002 en el orensano Parque de San Lázaro. 


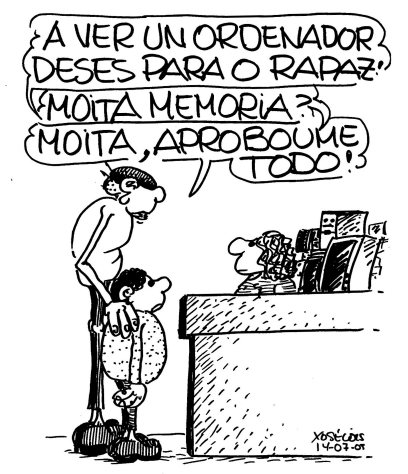

Figura 4: Xosé Lois, O Carrabouxo, La Región, 2009

Xesús Campos Álvarez, más conocido cómo Chichi Campos, nació en la Laguna (Tenerife) en 1952 y falleció en Santiago de Compostela en 1991. Fue uno de los más inteligentes y prolíficos humoristas gallegos, lleno de ingenio e ironía, pero su prematura muerte, el 26 de febrero de 1991, cuando apenas tenía 38 años, privó a Galicia de lo mejor de su carrera. Cofundó a principios de los 70, con Xosé Díaz Arias y Luís Caparrós Esperante, el grupo de cómic del Castro, que publicaría desde Suiza un único número de la revista $A$ Cova das Choias (1974). Su obra es un testimonio humorístico, subversivo e irreverente de la Transición, con especial predilección por los estamentos político, económico, religioso y militar de la época. Colaboró en numerosas publicaciones gallegas y foráneas ( $A$ Voz do Pobo, Mundo Obrero, A Nosa Terra, La Voz de Galicia, El Ideal Gallego, El Progreso, La Región), además de ser guionista de la recién nacida TVG.

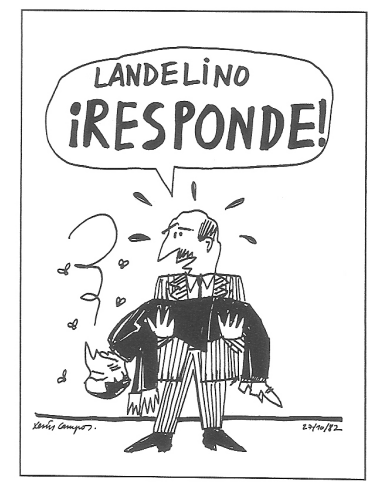

Figura 5: Chichi Campos, Landelino Lavilla.

Gogue (José Rodríguez López, O Grove, 1953) es también padre de un personaje muy popular, Floreano, tanto que comparte con el Carrabouxo de Xosé Lois el honor de tener una estatua propia. A Floreano, al que Gogue dibuja diariamente en Faro de Vigo desde 1989, lo inmortalizó en bronce Lucas Míguez. La estatua se levantó en julio de 2011 en la Plaza de Arriba de O Grove, enfrente de la casa natal del humorista. Gogue es, además, un excelente caricaturista, con una gran reputación en los Estados Unidos, donde colabora en diversas publicaciones desde hace muchos años. 


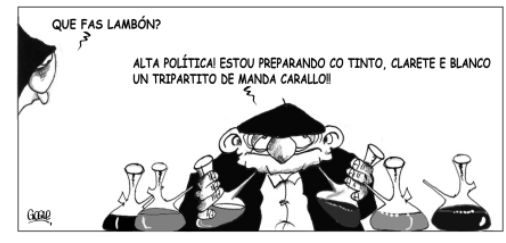

Figura 6: Gogue, Floreano, Faro de Vigo.

Pepe Carreiro (Xosé Carreiro Montero, Vigo, 1954) es, con Xaquín Marín, el único humorista gráfico gallego de los actualmente en ejercicio que dibuja en gallego, según Siro (entrevista personal, 17-2-2012), aunque él discrepa de esta apreciación. Además es uno de los más críticos, como mostró en La Voz de Galicia, El Mundo (Galicia) o Xornal de Galicia, y de lo que da fe su libro recopilatorio Fraga na Galiza (Laiovento, 1997). Una crítica que acabó por cerrarle las puertas de los diarios.

Eu hoxe en día estou apartado dos medios precisamente pola censura. En revistas si estou publicando, pero agora éme practicamente imposible publicar en diarios, porque o que queren é xente dócil, que divirta un pouco, que conte o chiste do día e non se meta en máis problemas. (...) deixei de publicar en La Voz de Galicia por criticar os bombardeos sobre Iraq. (...) [El Mundo] cambiou de director e un día tivo unha chamada de atención de [Xesús] Pérez Varela [conselleiro de Cultura e Comunicación Social da Xunta de Galicia] e dixéronme que non podía publicar máis. Sentáronlle mal varias cousas, pero sobre todo un debuxo no que puña a Fraga como partido en cachos" (Caballero, 2012: 152153).

Carreiro fue uno de los principales artífices de las revistas Can sen Dono y Xo! En los últimos años se ha centrado en la ilustración editorial y el cómic infantil, con series como Os Bolechas y Os Barbanzóns, que han conseguido mucho éxito.

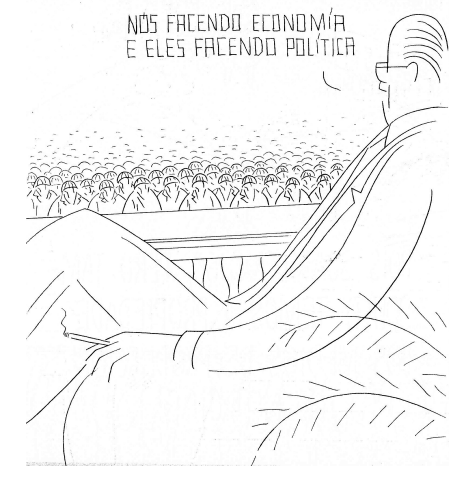

Figura 7: Pepe Carreiro, A Nosa Terra. 


\section{Conclusiones}

a) Las décadas de 1980 y 1990 confirman el resurgimiento del humor gráfico gallego, apuntado ya en los años 70, después de más de treinta años decadencia tras la Guerra Civil; y pueden ser consideradas las más importantes de la historia después de la edad de oro del género (1909-1936).

b) Este resurgimiento está ligado fundamentalmente a los nombres de Siro y Xaquín Marín, a los que pronto se sumará una pléyade de nuevos humoristas (Xosé Lois, Chichi Campos, Gogue, Pepe Carreiro...), sin olvidar a Quesada, que se había iniciado en la etapa anterior.

c) Esta revitalización supone la recuperación tanto del prestigio social del género y de su vinculación con Galicia y con el gallego como de la rica tradición de antes de la Guerra (Castelao, Maside, Cebreiro, Torres...), bien por la publicación de la obra de Castelao y de otros humoristas (desconocida por las generaciones más jóvenes), bien por el dibujo de algunos de los nuevos autores, como Siro, Xaquín Marín y Pepe Carreiro.

d) El punto de partida de esta nueva etapa es el I Seminario del Humor Gallego, celebrado en Sada en 1982, y su elemento desencadenante, la campaña llevada a cabo por Siro y Xaquín Marín en torno al Manifesto en defensa do humor.

e) En los años 80 y primeros 90 se aceleran los acontecimientos felices para el humor gráfico gallego, con cuatro grandes polos: la colaboración en los diarios de humoristas autóctonos comprometidos con la realidad del país, la celebración de los encuentros de humoristas, la publicación de las primeras revistas de humor desde la Guerra Civil (Can sen Dono, Xo! y Sapoconcho) y la fundación del Museo do Humor de Fene.

f) El impulso de los años 80 llega hasta la década de 2000 con iniciativas como la Bienal da Caricatura de Ourense y los suplementos humorísticos Xatentendo.com y O Farelo.

\section{Referencias bibliográficas}

AELG (2013). "Premios AELG 2013" en la página web de la Asociación de Escritoras e Escritores en Lingua Galega (AELG), 4 de mayo de 2013. Disponible en internet (6-11-2013): http://www.aelg.org/GetActivityByld.do?id=280

BALIÑAS, C. (1984). "Eso da risa, a broma e mais o humor", en I Seminario Galego do Humor, Sada, Ediciós do Castro, pp. 13-21. 
BARRERO, Manuel (2007). Sátira, intromisión y transgresión. El humor como atentado gráfico. En VVAA. Morfología del humor II. Fabricantes. Jornadas de estudio y análisis del humor desde la antropología, la psicología, la filosofía y cotidianidad (pp. 23-82). Sevilla: Padilla Libros Editores \& Libreros. Disponible en PDF en http://books.google.es (última consulta el 9-10-2014).

CABALLERO, F. (2012): O humor en cadriños, Cangas, Morgante.

CAMPOS, X. (1993). Xesús Campos. Unha visión aguda e vertixinosa de Galicia. Santiago de Compostela: Consorcio da Cidade de Santiago. Catálogo de la exposición del mismo título presentada en el Museo do Pobo Galego de Santiago de Compostela en septiembre/octubre de 1993.

CARREIRO, P. (1997). Fraga na Galiza. Santiago de Compostela: Laiovento.

CASTELAO, D. A. R. (1961): Humorismo. Dibuxo humorístico. Caricatura, A Coruña, Real Academia Galega (conferencia dictada en A Coruña el 1 de marzo de 1920).

FERNÁNDEZ PAZ, A. (1984). "O cómic", en I Seminario Galego do Humor, Sada, Ediciós do Castro, pp. 22-30.

GALINDO ARRANZ, Fermín (2000). Guía de los géneros periodísticos. Santiago de Compostela: Tórculo, $226 \mathrm{pp}$.

GOGUE (2011). Historias Floreánicas II. O Grove: Todogrove.

GOMIS, L. (2008). Teoría de los géneros periodísticos. Barcelona: UOC.

GOMIS, Lorenzo (1987, 2a ed.). El medio media. La función política de la prensa. Barcelona: Mitre.

GONZÁLEZ PÉREZ, C. (1982). Os nosos humoristas: Castelao. Sada: Ed. do Castro.

GONZÁLEZ PÉREZ, C. (1982). Os nosos humoristas: Vidales Tomé. Sada: Ed. do Castro.

GONZÁLEZ PÉREZ, C. (1983). Os nosos humoristas: Maside. Sada: Ed. do Castro.

GONZÁLEZ PÉREZ, C. (1983). Os nosos humoristas: Padín. Sada: Ed. do Castro.

GONZÁLEZ PÉREZ, C. (1984). “Aproximación á historia do humor gráfico galego”, en I Seminario Galego do Humor, Sada, Ediciós do Castro, pp. XXX.

GONZÁLEZ PÉREZ, C. (1984). Os nosos humoristas: Xaime Prada. Sada: Ed. do Castro.

GONZÁLEZ PÉREZ, C. (1984): "Aproximación á historia do humor gráfico galego", en I Seminario Galego do Humor, Sada, Ediciós do Castro, pp. 31-62.

GONZÁLEZ PÉREZ, C. (1985). Os nosos humoristas: Torres. Sada: Ed. do Castro. 
GONZÁLEZ PÉREZ, C. (1986). "A modo de epílogo: 50 humoristas contemporáneos de Castelao", en CASTELAO, A. D. R. (1986). Castelao, 1886-1950. Madrid: Ministerio de Cultura. Dirección General de Bellas Artes y Archivos. Catálogo de la exposición celebrada en el Real Jardín Botánico de Madrid del 3 de marzo al 13 de abril de 1986 con motivo del centenario del nacimiento del artista.

GONZÁLEZ PÉREZ, C. (1986). Os nosos humoristas: Cebreiro. Sada: Ed. do Castro.

LEDO, C. (1984). "O humor como instrumento de autocrítica", en I Seminario Galego do Humor, Sada, Ediciós do Castro, pp. 63-66.

LÓPEZ, S. (1984). "A caricatura", en I Seminario Galego do Humor, Sada, Ediciós do Castro, pp. 71-73.

LÓPEZ, S. (1984). "Notas para unha filosofía do humor", en I Seminario Galego do Humor, Sada, Ediciós do Castro, pp. 67-70.

LÓPEZ, S. (1997). "Xaquín Marín, innovador do humor gráfico galego", en MARÍN, X. Feito a man, Santiago de Compostela: Consellería de Cultura e Comunicación Social de la Xunta de Galicia, pp.13-14.

LÓPEZ, S. (2009). A autonomía galega nas caricaturas de Siro. A Coruña: Deputación da Coruña.

LÓPEZ, S. y MARÍN, X. (2009). "Manifesto en defensa do humor". En LÓPEZ, S. y MARÍN, X. O humor desde Ferrol: Siro e Xaquín Marín. Ferrol: Club de Prensa de Ferrol, p. 7.

MARÍN, X. (1995). "A vida a través da perspectiva poliédrica do humor", en Humor gráfico galego, Santiago de Compostela, Consellería de Cultura / Xunta de Galicia, p. 11.

MARín, X. (1997). Feito a man. Santiago de Compostela: Consellería de Cultura da Xunta de Galicia.

MARTÍNEZ ALBERTOS, José Luis (2004, 5a ed.). Curso general de redacción periodística. Madrid: Paraninfo

MORÁN, Esteban (1988). Géneros del periodismo de opinión. Crítica, comentario, columna, editorial. Pamplona: Eunsa.

PANIAGUA, Pedro (2011). El humor en los diarios. La opinión (des)dibujada. En M. L. Sánchez Calero (ed.), Géneros y discurso periodístico (pp. 157-182). Madrid: Fragua. 
PASCUAL CARBALLO, A. (2009): Humor gráfico galego. Da transición ao século XXI, Vigo, Ir Indo.

QUESADA, F. (2011): Quesada. 1961-2011, Vigo, Faro de Vigo.

TEJEIRO SALGUERO, Ricardo y LEÓN GROSS, Teodoro (2009). "Las viñetas de prensa como expresión del periodismo de opinión", Diálogos de la Comunicación. Revista Académica de la Federación Latinoamericana de Facultades de Comunicación Social (Felafacs), no 78, enero-julio de 2009. Disponible en PDF el 12-2-2014 en http://dialnet.unirioja.es/servlet/articulo?codigo=3718808

XOSÉ LOIS (2002). 20 anos de Carrabouxo. Ourense: Deputación Provincial de Ourense. Entrevistas:

Xaquín Marín Formoso (Xaquín Marín): entrevista personal, Fene (A Coruña), 410-2012 / comunicación electrónica, 3-12-2010. En CABALLERO, F. (2012). O humor en cadriños. Cangas: Morgante, pp. 45-60.

Siro López (Siro): entrevista personal, A Coruña, 17-2-2012 / comunicación electrónica, 10-11-2010. En CABALLERO, F. (2012). O humor en cadriños. Cangas: Morgante, pp. 13-36.

Xosé Lois González Vázquez (Xosé Lois): comunicación electrónica, 24-12-2010. En CABALLERO, F. (2012). O humor en cadriños. Cangas: Morgante, pp. 71-93.

José Rodríguez López (Gogue): comunicación electrónica, 1-12-2010. En CABALLERO, F. (2012). O humor en cadriños. Cangas: Morgante, pp. 109-123.

Xosé Carreiro Montero (Pepe Carreiro): entrevista personal, Vigo (Pontevedra), 21-2-2011). En CABALLERO, F. (2012). O humor en cadriños. Cangas: Morgante, pp. 139-162.

Xosé Alberte Suárez Lage: comunicación telefónica, 25-9-2012.

Osvaldo Macedo de Sousa: entrevista personal, Oeiras (Portugal), 2-5-2013. 